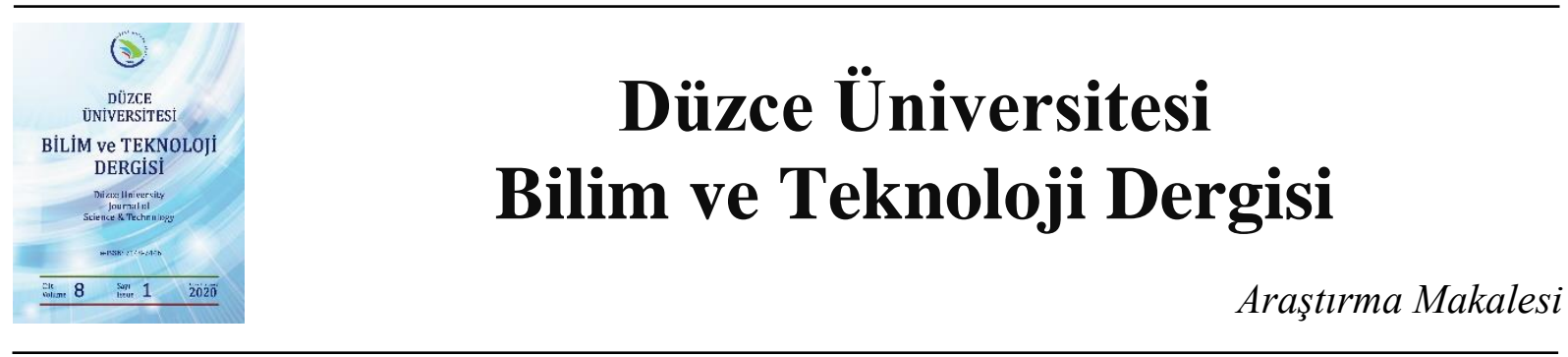

\section{Orman Ürünleri Sanayi Çalışanlarının İş Sağlığı Ve Güvenliğine Kaderci Bakış Açılarının Tespit Edilmesine Yönelik Bir Alan Araştırmas1*}

\author{
Aytaç AYDIN a,*, (DD Gizem CEYLAN a \\ ${ }^{a}$ Orman Endüstri Mühendisliği Bölümü, Orman Fakültesi, Karadeniz Teknik Üniversitesi, Trabzon, TÜRKIYYE \\ * Sorumlu yazarin e-posta adresi: aytac@ktu.edu.tr
}

DOI: $10.29130 /$ dubited.652938

\begin{abstract}
ÖZET
Bu çalışmada, orman ürünleri sanayi işletmelerinde çalışanların iş sağlığı ve güvenliği uygulamalarına bakışlarının kaderci yaklaşım çerçevesinde nasıl şekillendiği tespit edilmiştir. Bu amaçla hazırlanan anket formu İzmir ve Balıkesir illerinde bulunan sekiz orman ürünleri işletmesinde çalışan 470 kişi üzerinde uygulanmış ve istatistiksel analizler yapılarak sonuçlar ortaya koyulmuştur. Sonuçlar incelendiğinde, kaderci yaklaşımın eğitim durumu, cinsiyet, iş kazası geçirme durumu ve orman ürünleri alt sektörleri düzeyinde anlamlı farklılıklar gösterdiği belirlenmiştir. Bununla birlikte, kaderci yaklaşımın toplam çalışma süresi, medeni durum ve yaş gruplarına göre farklılık göstermediği ortaya çıkmıştır. İş kazalarının yaklaşı \%99'unun önlenebilir niteliğe sahip olduğu göz önüne alındığında, orman ürünleri çalışanları arasında kaderci yaklaşım düzeylerinin yüksekliği ve değişkenliğinin önemli bir sorun olarak görülmesi gerektiği aşikârdır.
\end{abstract}

Anahtar Kelimeler: Orman ürünleri sanayi, İşsağllğ ve güvenliği, Kadercilik

\section{A Field Study on Determining Fatalistic Perspectives of Occupational Health and Safety of Forest Products Industry Employees}

\begin{abstract}
In this study, it has been determined how the view of occupational health and safety practices of forestry industry enterprises are shaped within the framework of fatalistic approach. The questionnaire prepared for this purpose was applied to 470 people working in eight forest products enterprises in İzmir and Balıkesir provinces and the results of statistical analyzes were performed. When the results were examined, it was determined that the fatalistic approach showed significant differences in the level of education, gender, occupational accident and forest products sub-sectors. However, it was found that the fatalistic approach did not differ according to the total working time, marital status and age groups. Considering that $99 \%$ of occupational accidents are preventable, it is clear that the high level and variability of fatalistic approach among forest workers should be seen as an important problem.
\end{abstract}

Keywords: Forest products industry, Occupational health and safety, Fatalism

Geliş: 30/11/2019, Düzeltme: 17/12/2019, Kabul: 10/01/2020

* Bu çalışma KTÜ Fen Bilimleri Enstitüsü, Orman Endüstri Müh. Anabilim Dalında Yüksek Lisans Tezi olarak kabul edilmiştir. 


\section{GIRIS}

Endüstrileşmenin hızla gelişip ilerlediği çağımızın önemli ve hassas konularından biri de iş sağlığı ve güvenliği olmuştur. İnsan faktörünün olduğu her alanda, sağlik ve güvenlik de beraberinde gelmektedir. Diğer yandan, sanayileşmeyle birlikte çalışma ortamında iş kazaları ve meslek hastalıkları gibi sorunlar meydana gelmektedir. Bunun sonucunda çalışanlar yaralanabilmekte, sakat kalabilmekte ve hatta hayatlarını kaybedebilmektedirler.

İş kazası sayıları incelendiğinde Türkiye, dünyada ikinci Avrupa'da ise birinci sırada yer almaktadır [1]. $\mathrm{Bu}$ nedenle iş sağlığı ve güvenliği çalışmalarının daha fazla sayıda yapılması gerekliliği görülmektedir. Orman ürünleri sanayi sektörü ise genel olarak yüksek risk grubu içeren sektörler arasında yer almaktadır. Orman ürünleri sanayi sektörü 34.266 işyeri ve 274.509 çalışana sahip çoğunluğu KOBİ niteliğine sahip işletmelerden oluşan bir yapıya sahiptir. Sosyal Güvenlik Kurumu (SGK) kayıtlarına göre orman ürünleri sektöründe meydana gelen iş kazası, meslek hastalığı sayıları Tablo 1'de verilmiştir [2].

Tablo 1. 2013-2016 yılları arasındaki işgöremezlik sürelerine göre iş kazası geçiren ve meslek hastalıklarına tutulan sigortalı saylart

\begin{tabular}{lcccccc}
\hline Yıllar & \multicolumn{2}{c}{ İs Kazası Geçiren Sigortalı Sayıları } & \multicolumn{3}{c}{$\begin{array}{c}\text { Meslek Hastalığına Tutulan } \\
\text { Sigortalı Sayısı }\end{array}$} \\
\cline { 2 - 7 } & Erkek & Kadın & Toplam & Erkek & Kadın & Toplam \\
\hline $\mathbf{2 0 1 3}$ & 8.148 & 300 & 8.448 & 2 & 0 & 2 \\
\hline $\mathbf{2 0 1 4}$ & 9.101 & 493 & 9.594 & 3 & 0 & 3 \\
\hline $\mathbf{2 0 1 5}$ & 9.125 & 586 & 9.801 & 7 & 0 & 7 \\
\hline $\mathbf{2 0 1 6}$ & 9.697 & 673 & 10.370 & 7 & 0 & 7 \\
\hline $\mathbf{2 0 1 7}$ & 11.468 & 842 & 12.310 & 10 & 0 & 10 \\
\hline
\end{tabular}

Tablo 1 incelendiğinde iş kazası geçiren ve meslek hastalığına yakalanan çalışan sayısında sürekli bir artış olduğu göze çarpmaktadır. Orman ürünleri sanayi sektörü kimyasal maddelerin üretim sürecinde kullanılması sebebiyle risk düzeyi yüksek sektörler içerisinde değerlendirilmektedir [3]. Sektör genelinde KKD kullanımının düşük, fiziksel koşulların yetersiz olması iş güvenliği açısından problemler yaratmaktadır $[4,5]$. Bununla beraber iş güvenliği eğitimlerinin yetersizliği de önemli bir sorun olarak öne çıkmaktadır [6]. Çalışma ortamında gerek makine gerekse iş düzeninden kaynaklı gürültü oluşumu çalışanlarda fizyolojik ve psikolojik rahatsızlıklara neden olabilmektedir [7, 8].

İş kazası ve meslek hastalıklarının nedenleri genel olarak incelendiğinde \%79,5'inin güvensiz hareketler (şakalaşmalar, Kişisel Koruyucu Donanım (KKD) kullanılmaması, dikkatsiz çalışan hali, araç-gereç ve donanımları düzensiz kullanma, çalışma halindeyken işçilerin birbirini kızdırması vb), \% 19,5'inin güvensiz şartlar (ortam koşulları, KKD'lerin verilmemiş olması, uygun olmayan çalışma yöntemleri, makine koruyucularının uygunsuzluğu, makine koruyucusunun olmaması, yapılmayan bakım ve kontroller, servis kazası, düzensizlik, kusurlu olan araç ve gereçler, ergonomi şartlarına uyulmaması) ve $\%$ 1'inin bilinmeyen nedenlerle ortaya çıktığı görülmektedir [9].

$\mathrm{Bu}$ faktörlerle birlikte çalışanların iş kazasına uğrama nedeni olarak ortaya çıkan bir diğer etken de olacak olanın önüne geçilemeyeceğinin düşünüldüğü kaderci bakış açısının yaygın bir algı olmasıdır. Kaderci bakış, insanın karşılaşabileceği olayların önceden belirlendiği ve bunun değişmesinin mümkün olmadığı yaklaşımıdır. Çalışma ortamında kadercilik ise çalışanın iş ortamında karşılaşabileceği risk faktörleri neticesinde kazaların kaçınılmaz bir sonuç olduğudur [10].

İş kazası oluşum modellerinden biri olan kaza yatkınlık modeli, iş kazalarının kaderci davranış gösteren çalışanların güvensiz hareketlerinden kaynaklandığını ortaya koymaktadır [11]. Bir diğer model olan kazaya temayül modeli de iş kazasının bütün nedeninin çalışan hataları olduğunu ifade ederek kazaların kaçınılmaz olduğunu iddia etmektedir [12]. Kaderci yaklaşım gösteren toplumsal yapı içerisinde İSG 
kültürünün oluşturulması oldukça zor olup bireysel kültürün etkin olduğu toplumlarda ise İSG kültürünün daha kolay oluşturulabileceği ifade edilmektedir [13].

$\mathrm{Bu}$ çalışmada orman ürünleri sanayinde faaliyet gösteren işletmelerdeki çalışanların kaderci bakış açılarının alt sektörler düzeyinde ve bazı demografik özelliklere göre farklılaşma durumlarının tespit edilmesi amaçlanmıştır.

\section{MATERYAL VE YÖNTEM}

Çalışma kapsamında iş sağlığı ve güvenliği konusunun önemli bir parçası olan kaderci yaklaşımın orman ürünleri sanayinde alt sektörler düzeyinde nasıl algılanıp değerlendirildiğinin tespit edilmesi amacıyla anket formu hazırlanarak analizler yapılmıştır. Anket çalışması, 2017 yılı Ocak- Haziran ayları arasında İzmir ve Balıkesir illerinde bulunan 3 tane kereste, 3 tane mobilya, 1 tane levha, 1 tane kağıt olmak üzere toplam 8 adet fabrikada yapılmıştır. SGK kayıtlarına göre 2017 yılı itibariyle İzmir ve Balıkesir illerinde orman ürünleri sanayinde toplam 24.748 çalışan olduğu ifade edilmiştir [2]. Bu bağlamda \% 95 güven düzeyinde erişilmesi gereken örneklem büyüklüğü 378 olarak hesaplanmış, anket güvenilirliği ve hataların azaltılması amacıyla daha fazla anket yapılması planlanmıştır. Uygulamada ilgili fabrikalardaki tüm çalışanlara anket formu dağıtılmış ve değerlendirilebilir nitelikte olan 470 form dikkate alınmıştır.

Anket formu, bazı demografik özellikler (7 soru) ve iş sağlığı güvenliği algısının tespit edilmesine yönelik hazırlanmış beşli likert tipi yargılar (66 yargı) içeren iki bölümden oluşmaktadır ve literatürde yapılan çalışmalardan derlenen yargılar kullanılarak anket soruları oluşturulmuştu [8, 14-23]. Verilerin analizinde SPSS (Statistical Package for Social Sciences) istatistik paket programı ve MS Excel paket programları kullanılmıştır. Değerlendirmede frekans dağılımları, güvenirlik analizi, bağımsız iki örnek t- testi, basit varyans analizi kullanılmıştır. Analizler yapılırken iki alt değişkene sahip demografik özellikler t- testi, ikiden fazla alt değişkene sahip demografik özellikler ise tek yönlü varyans analizi kullanılarak test edilmiştir. Varyans analizi uygulanırken varyansların homojenliği incelenmiş, homojenliğin sağlandığg durumlarda Anova testi ve Duncan testi, sağlanamadığı durumlarda Welch testi ve Dunnett C testi kullanılmıştır.

\section{BULGULAR}

\section{A. ÖLÇEK GEÇERLIILİĞİ VE GÜVENILİRLİĞí}

Çalışma kapsamında ortaya konulan ölçek geçerliliği Kaiser-Mayer-Olkin (KMO) testiyle incelenmiş̧tir. KMO gözlenen korelasyon katsayıları büyüklüğ̈̈ ile kısmi korelasyon katsayılarının büyüklüğünü karşılaştıran bir indekstir ve geçerlilik için bu oranın 0,5 'in üzerinde olması gerekmektedir [24]. Ölçeğe ait KMO değerinin 0,883 (Bartlett's Test of Sphricity Sig.:0,001), ölçeğe ait cronbach's alpha katsayısının 0,886 olduğu tespit edilmiştir. Literatürde bu değerin 0 ile 1 arasında değerler aldığ ve 0,60 üzerindeki değerlere sahip ölçeklerin oldukça güvenilir oldukları görülmektedir [25].

\section{B. DEMOGRAFİK FAKTÖRLERE İLISSKİN BULGULAR}

Uygulanan anket çalışması ile katılımcıların eğitim durumu, yaş dağılımı, cinsiyet, medeni durum, toplam çalışma süresi, iş kazası geçirme durumları ve faaliyet alanlarının tespit edilmesi amaçlanmıştır. Bu sorulara ilişkin verilen cevapların dağılımları Tablo 2'de verilmiştir. 
Tablo 2. Demografik faktörlere ilişkin dağılımlar

\begin{tabular}{|c|c|c|c|}
\hline Demografik özellikler & & $\begin{array}{c}\mathbf{N} \\
\text { (adet) }\end{array}$ & $\begin{array}{c}\text { Frekans } \\
(\%)\end{array}$ \\
\hline \multirow{4}{*}{ Eğitim durumu } & İlköğretim & 207 & 44,0 \\
\hline & Lise & 198 & 42,1 \\
\hline & Yüksekokul & 36 & 7,7 \\
\hline & Üniversite & 26 & 5,5 \\
\hline \multirow{4}{*}{ Yaş } & $18-30$ & 110 & 23,4 \\
\hline & $31-40$ & 201 & 42,8 \\
\hline & $41-50$ & 137 & 29,1 \\
\hline & $51-60$ & 18 & 3,8 \\
\hline \multirow{2}{*}{ Cinsiyet } & Erkek & 427 & 90,9 \\
\hline & Kadın & 23 & 4,9 \\
\hline \multirow{2}{*}{ Medeni durum } & Evli & 351 & 74,7 \\
\hline & Bekar & 89 & 18,9 \\
\hline \multirow{3}{*}{ Toplam çalışma süresi } & $0-5$ & 223 & 47,4 \\
\hline & $6-10$ & 96 & 20,4 \\
\hline & $11-20$ & 143 & 30,4 \\
\hline \multirow{2}{*}{$\begin{array}{l}\text { İş kazası } \\
\text { durumları }\end{array}$} & Evet & 98 & 20,9 \\
\hline & Hayır & 342 & 72,8 \\
\hline \multirow{4}{*}{ Faaliyet alanları } & Mobilya & 231 & 49,1 \\
\hline & Kereste & 35 & 7,4 \\
\hline & Levha & 112 & 23,8 \\
\hline & Kağıt & 92 & 19,6 \\
\hline
\end{tabular}

Araştırmaya katılanların \%44' ü ilköğretim mezunu olup, bunu \%42,1 ile lise mezunları takip etmektedir. Katılımcıların \%42,8' inin 31-40 yaş aralığında, \%90,9' unun erkek, \%74,7'sinin evli, \%18,9'unun bekâr çalışanlardan oluştuğu görülmektedir. Çalışanların \%20,9' u iş kazasına maruz kaldığını belirtirken, \%72,8' i iş kazasına uğramadığını ifade etmiştir. Faaliyet alanlarına göre incelendiğinde ise katılımcıların; \%49'1'inin mobilya, \%7,4'ünün kereste, \%23,8'inin levha ve \%19,6’sının kâğıt sektöründe çalıştı̆̆ı belirlenmiştir.

\section{DEMOGRAFIK FAKTÖRLER ILE KADERCİ YAKLAŞIM ARASINDAKİ FARKLILIKLAR}

$\mathrm{Bu}$ bölümde katılımcılara ait demografik özelliklere göre kaderci yaklaşımın farklılık gösterip göstermediği araştırılmıştır. Tablo 3'de kaderci yaklaşımın eğitim durumuna göre farklılaşma durumu görülmektedir.

Tablo 3. Ĕ̆itim durumuna göre kaderci yaklaşım

\begin{tabular}{llcccc}
\hline Demografik özellik & & Ortalama & Post Hoc** & f** & p \\
\hline \multirow{4}{*}{ Ĕgitim durumu } & İlköğretim & 2,81 & $\mathrm{a}$ & & \\
\cline { 2 - 4 } & Lise & 2,52 & $\mathrm{a}$ & & \\
\cline { 2 - 4 } & Yüksekokul & 2,27 & $\mathrm{ab}$ & 0,001 \\
\cline { 2 - 4 } & Üniversite & 2,04 & $\mathrm{c}$ & & \\
\hline
\end{tabular}

** tek tönlü varyans analizi

Kadercilik ile eğitim durumu arasında da anlamlı farklılıklar tespit edilmiştir $(\mathrm{p}<0,05)$. Tablo 3 incelendiğinde lise mezunu çalışanlar hem ilköğretim mezunu hem de yüksekokul mezunu çalışanlarla benzerlik gösterirken, yüksekokul mezunu çalışanlar hem lise mezunu hem de üniversite mezunu çalışanlarla benzerlik göstermektedir. İlköğretim mezunu çalışanlar, yüksekokul ve üniversite mezunu çalışanlardan farklı grupta yer almaktadır. İlköğretim mezunu çalışanların kaderciliğe katılımlarının 
diğer eğitim düzeyindeki çalışanlardan daha yüksek olduğu tespit edilmiştir. Yıldız ve Yılmaz yaptıkları araştırmada eğitim seviyesi ile kadercilik arasında anlamlı farklılık olduğunu, artan eğitim seviyesi ile kaderci yaklaşım ortalamasının düştüğünü ortaya koymuştur [26]. Dursun, çalışmasında benzer olarak anlamlı farklılık olduğunu ifade etmiştir [27]. Bununla birlikte, Öztürk ise yaptığı çalışmada, kadercilik ile eğitim durumu arasında anlamlı bir farklılık tespit etmemiştir [28]. Tablo 4'te yaş gruplarına göre kaderci yaklaşımın farklılaşma durumu verilmiştir.

Tablo 4. Yaş gruplarına göre kaderci yaklaşım

\begin{tabular}{lccccc}
\hline Demografik özellik & & Ortalama & Post Hoc*** & f** & p \\
\hline \multirow{4}{*}{ Yaş } & $18-30$ & 2,56 & & & \\
\cline { 2 - 3 } & $31-40$ & 2,60 & - & 0,068 & 0,977 \\
\cline { 2 - 3 } & $41-50$ & 2,61 & & & \\
\cline { 2 - 3 } & $51-60$ & 2,63 & & & \\
\hline
\end{tabular}

** tek tönlü varyans analizi

Tablo incelendiğinde kaderci yaklaşım ile yaş grupları arasında istatistiksel olarak anlamlı farklılık bulunmadığı tespit edilmiştir ( $>0,05)$. Bununla birlikte ortalamalar incelendiğinde artan yaşa bağlı olarak kaderci yaklaşım yargılarına katılımın arttığı görülmüştür. Yılmaz ve Yıldız'da çalışanların yaş değişiminin kaderciliği etkilemediğini belirtmişlerdir [26]. Havold yaptığı çalışmada ilerleyen yaşa bağlı olarak bilgi ve deneyimin artmasının güvenlik tutumunu iyileştirdiğini, kaderciliği ise azalttığını ifade etmiştir [29]. Tablo 5'de cinsiyete göre kaderci yaklaşımın farklılaşma durumu verilmiştir.

Tablo 5. Cinsiyete göre kaderci yaklaşım

\begin{tabular}{|c|c|c|c|c|}
\hline Demografik özellikler & & Ortalama & $\mathbf{t}^{*}$ & $\mathbf{p}$ \\
\hline \multirow{2}{*}{ Cinsiyet } & Erkek & 2,57 & $-2,709$ & 0,007 \\
\hline & Kadın & 3,12 & & \\
\hline
\end{tabular}

* t testi

Tabloya göre kadercilik ile cinsiyet arasında istatistiksel olarak anlamlı farklılık tespit edilmiştir $(\mathrm{p}<0,05)$. Kadın çalışanların kaderciliğe katılımlarının erkek çalışanlardan daha yüksek olduğu görülmüştür. Bununla birlikte, Dursun, çalışmasında cinsiyet ile kaderci yaklaşım arasında ilişki tespit etmemiştir [11]. Tablo 6'da medeni duruma göre kaderci yaklaşımın farklılaşma durumu verilmiştir.

Tablo 6. Medeni duruma göre kaderci yaklaşım

\begin{tabular}{llccc}
\hline Demografik özellikler & & Ortalama & $\mathbf{t}^{*}$ & $\mathbf{p}$ \\
\hline \multirow{2}{*}{ Medeni durum } & Evli & 2,59 & 0,033 & 0,974 \\
\cline { 2 - 3 } & Bekar & 2,59 & & \\
\hline
\end{tabular}

* t testi

Yukarıdaki tabloya göre; kadercilik ile medeni durum arasında istatistiksel olarak anlamlı farklılık bulunmadığ 1 tespit edilmiştir ( $>00,05)$. Yıldız ve Yılmaz çalışmalarında kaderci yaklaşımın medeni duruma göre farklılık gösterdiğini, evlilerin bekarlara göre daha kaderciliğe daha yüksek oranda katıldıklarını ifade etmiştir [26]. Tablo 7'de toplam çalışma süresine göre kaderci yaklaşımın farklılaşma durumu verilmiştir.

Tablo 7. Toplam çalışma süresine göre kaderci yaklaşım

\begin{tabular}{|c|c|c|c|c|c|}
\hline Demografik özellikler & & Ortalama & Post Hoc** & $\mathbf{f}^{* * *}$ & $\mathbf{p}$ \\
\hline \multirow{3}{*}{ Toplam çalışma süresi } & $0-5$ & 2,67 & \multirow{3}{*}{ - } & \multirow{3}{*}{2,851} & \multirow{3}{*}{0,059} \\
\hline & $6-10$ & 2,70 & & & \\
\hline & $11-20$ & 2,45 & & & \\
\hline
\end{tabular}

** tek tönlü varyans analizi 
Tablo incelendiğinde kadercilik ile toplam çalışma süresi arasında istatistiksel olarak anlamlı farklılık bulunmadığı tespit edilmiştir ( $>0,05)$. Bununla birlikte özellikle 11 yıldan fazla çalışanlarda kaderci yaklaşım yargılarına katılımın diğer çalışanlara göre daha düşük olduğu göze çarpmaktadır. Yılmaz ve Yıldız ile Dursun yaptıkları çalışmalarda çalışma süresi ile kadercilik arasında anlamlı bir farklılık tespit etmemişlerdir [26, 27]. Tablo 8'de iş kazası geçirme durumuna göre kaderci yaklaşımın farklılaşma durumu verilmiştir.

Tablo 8. Iş kazası geçirme durumuna göre kaderci yaklaşım

\begin{tabular}{llccc}
\hline Demografik özellikler & & Ortalama & t* & p \\
\hline \multirow{2}{*}{ İş kazası geçirme durumu } & Evet & 2,36 & \multirow{2}{*}{$-2,427$} & 0,016 \\
\cline { 2 - 3 } & Hayır & 2,62 & & \\
\hline
\end{tabular}

* t testi

Analiz sonucunda kadercilik ile iş kazası geçirme durumları arasında istatistiksel olarak anlamlı farklılık tespit edilmiştir $(\mathrm{p}<0,05)$. İş kazası geçiren çalışanların kaderciliğe katılımlarının iş kazası geçirmeyen çalışanlardan daha yüksek olduğu görülmüştür. Bu durumun; iş kazası geçirenlerin kazanın kader olmadığını daha iyi algılandığının bir sonucu olarak ortaya çıktığı düşünülmektedir. Bununla birlikte Dursun yaptığı çalışmada işyerinde kaza geçirme durumu ile kaderci yaklaşım arasında farklılık tespit etmemiştir [27]. Tablo 9'da faaliyet alanına göre kaderci yaklaşımın farklılaşma durumu verilmiştir.

Tablo 9. Faaliyet alanına göre kaderci yaklaşım

\begin{tabular}{lllcll}
\hline Demografik özellikler & & Ortalama & Post Hoc** & f** $^{* *}$ & p \\
\hline \multirow{4}{*}{ Faaliyet alanları } & Mobilya & 2,58 & $\mathrm{a}$ & & \\
\cline { 2 - 4 } & Kereste & 3,51 & $\mathrm{~b}$ & \multirow{2}{*}{0,642} & 0,001 \\
\cline { 2 - 4 } & Levha & 2,48 & $\mathrm{a}$ & & \\
\cline { 2 - 4 } & Kağıt & 2,43 & $\mathrm{a}$ & & \\
\hline
\end{tabular}

** tek tönlü varyans analizi

Kadercilik ile faaliyet alanları arasında anlamlı farklılıklar tespit edilmiştir $(\mathrm{p}<0,05)$. Mobilya, levha ve kâğıt sektörlerinde çalışanların kendi aralarında benzerlik gösterdiği görülürken, kereste sektöründe çalışanların farklı grupta yer aldığı tespit edilmiştir. Kereste sektöründe çalışanların kaderciliğe katılımlarının diğer sektörde çalışanların katılımlarından daha yüksek olduğu tespit edilmiştir.

\section{IV.SONUC}

Bu çalışma kapsamında orman ürünleri sanayinde faaliyet gösteren işletmelerdeki çalışanların kaderci bakış açılarının alt sektörler düzeyinde ve bazı demografik özelliklere göre farklılaşma durumlarının tespit edilmesi amaçlanmıştır. Çalışma sonuçları incelendiğinde, katılımcıların çoğunluğunun ilköğretim ve lise mezunu olduğu, 31-40 yaş grubunda olduğu, erkek olduğu ve evli olduğu belirlenmiştir. Ayrıca \%47,4'ünün 0-5 y1l tecrübe sahibi olduğu ve \%72,8'inin iş kazası geçirmediği ortaya çıkmıştır. Katılımcıların faaliyet alanları incelendiğinde \%49,1'inin mobilya sektöründe \%23,8'inin levha sektöründe, \%19,6'sının kağıt ve \%7,4'ünün kereste sektöründe yer aldıkları görülmüştür.

İfade edilen bu demografik özelliklere bağlı olarak kaderci yaklaşımda farklılaşma olup olmadığına yönelik analizler yapılmıştır. Bu analizlere göre, eğitim durumu ile kaderci yaklaşım arasında anlamlı farklılık tespit edilmiş olup, eğitim seviyesinin yükselmesi ile kaderci yaklaşıma katılımda düşüş meydana getirmiştir. Cinsiyet değişkenine göre kaderci yaklaşım arasında anlamlı farklılık tespit edilmiş, kadınların erkeklere göre daha kaderci bir yaklaşım sergiledikleri belirlenmiştir. İş kazası geçirme durumlarına göre kaderci yaklaşım arasında anlamlı farklılık tespit edilmiş, iş kazası geçirenlerin kaderci yaklaşım yargılarına katılımlarının daha düşük olduğu görülmüsştür. Ayrıca orman 
ürünleri alt sektörleri düzeyinde de kaderci yaklaşım farklılığı tespit edilmiştir. Özellikle kereste sektörü çalışanlarının kaderci yaklaşım yargılarına katılımının oldukça yüksek olduğu ortaya çıkmıştır.

Bununla birlikte kaderci yaklaşım ile toplam çalışma süresi, medeni durum ve yaş grupları arasında anlamlı farklılıklar tespit edilmemiştir. Yapılan analizler ve elde edilen sonuçlara bağlı olarak yapılabilecek öneriler şöyle sıralanabilir:

- Çalışma sonuçlarına göre eğitim seviyesinin yükselmesi kaderci bakış düzeyini azaltmaktadır. Bu nedenle pozisyona uygun olmak kaydıyla eğitim düzeyi yüksek çalışanların işlendirilmesi, ayrıca mevcut çalışanların da hizmet içi eğitimler ile bilinçlendirilmesi önem arz etmektedir.

- Kadın çalışanların kaderci bakış düzeyleri erkeklere oranla daha yüksek tespit edilmiştir. Sektörde kadın çalışan sayısı oransal olarak az olsa da verilecek eğitim içeriği özelleştirilerek kadın çalışanların kaderci bakış durumları düzeltilebilir.

- İş kazası geçiren çalışanların kaderci yaklaşıma katılımlarının daha düşük olduğu belirlenmiştir. Bu noktada önemli olan iş kazası geçirmeden bu bilince ulaşacak tedbirlerin alınması hem bireysel hem de toplumsal olumsuzlukların önüne geçecektir.

- Orman ürünleri alt sektörleri arasında en yüksek katılım kereste sektöründe görülmüsstür. Kereste sektörü üretim sistemi gereği iş kazasına en yatkın sektör olarak öne çıkmaktadır. Bu bağlamda kereste sektörü işletmelerinin iş sağlığı ve güvenliği çalışmalarına daha fazla önem vermesi gerektiği ortaya çıkmaktadır.

\section{KAYNAKLAR}

[1] H. Serin, Y. Şahin, M. Durgun ve A. Şimsek, "A Research on Work Accidents at Manufacturing Sector with Regard to Physical Environment Conditions," 14th International Scientific Conference of the University of Sibiu, Romanya, 2015, ss. 358-366.

[2] Anonim, (2018, 10 Ocak). [Online]. Erişim: http://www.sgk.gov.tr/wps/portal/sgk/tr/ kurumsal/istatistik/sgk_istatistik_yilliklari.

[3] H. Kim ve D. Park, "Selecting High-Risk Micro-Scale Enterprises Using A Qualitative Risk Assessment Method," Industrial Health, s. 44, ss. 75-82, 2006.

[4] Y. Top, H. Adanur ve M. Öz, "Comparison of Practices Related to Occupational Health and Safety in Microscale Wood-Product Enterprises,” Safety Science, s. 82, ss. 374-381, 2016.

[5] T. Gedik ve A. İlhan, "Sakarya İli Mobilya İmalatçılarında İş Sağlığg ve İş Güvenliği Üzerine Bir İnceleme,” Türkiye Ormancılık Dergisi, c. 15 s. 2, ss. 123-129, 2014.

[6] A. İlhan, G. Koşar, A. Karapınar ve T. Gedik, "Analysis of Underlying Causes of the Occupational Accidents and Diseases in Furniture," Kastamonu University Journal of Forestry Faculty, c. 13 s. 2, ss. 202-210, 2013.

[7] H. Serin, Y. Şahin, ve M. Durgun, "Küçük Ölçekli Mobilya İşletmelerinde Gürültü Analizi," Ormancllık Dergisi, c. 9 s. 2, ss. 1-8, 2013.

[8] Y. Seyhan, “Ankara İlinde, Ağaç İşleri Sektöründe Faaliyet Gösteren Orta ve Büyük Ölçekli İşletmelerde İş Sağlığı ve İş Güvenliği Üzerine Araştırmalar," Yüksek Lisans Tezi, Orman Endüstri Mühendisliği Bölümü, Bartın Üniversitesi, Bartın, Türkiye, 2009. 
[9] C. D. Temel, "İnşaat İşçilerinin İş Sağlığı ve Güvenliği Konusunda Uygulama ve Algılama Düzeyi," Yüksek Lisans Tezi, İnşaat Mühendisliği Bölümü, Çukurova Üniversitesi, Adana, Türkiye, 2017.

[10] Ö. Yavan, "Çalışanların İşe Gitmeme ve Çalışıyor Gibi Görünme Davranışları Üzerine Bir Araştırma: Zonguldak Taşkömürü Kurumu Örneği,” UiïID, s. 19, ss. 249-276, 2017.

[11] M. D. Cooper, "Towards A Model of Safety Culture,” Safety Science, s. 36, ss. 111-136, 2000.

[12] T. Demirbilek, Işs Güvenliği Kültürü, İstanbul, Türkiye: Legal Yayıncılık, 2005.

[13] B. Güven, "İş Güvenliği ve İşgören Sağllğı Kültürü ve Örgütsel Vatandaşl1k Davranış1," Doktora Tezi, İşletme Bölümü, Atatürk Üniversitesi, Erzurum, Türkiye, 2014.

[14] D. Tiryaki, "İş Sağlığı ve Güvenliğindeki Gelişmeler: Altınova Tersaneleri Çalışanlarının Farkındalıklarının Değerlendirilmesi," Yüksek Lisans Tezi, İşletme Bölümü, Yalova Üniversitesi, Yalova, Türkiye, 2011.

[15] E. Güngör, “İş Sağlı̆̆ı ve Güvenliği Kavramlarının Toplam Kalite Yönetimi Açısından İrdelenmesi ve Talaşlı Üretim Sanayisinde İş Sağlığı ve Güvenliği Üzerine Bir Araştırma," Yüksek Lisans Tezi, İşletme Bölümü, Marmara Üniversitesi, İstanbul, Türkiye, 2008.

[16] A. Durdu, "Isş̧̧i Sağlığ1 ve İş Güvenliği Düzenlemeleri ile İlgili İşgörenlerin Tutumlarını Belirlemeye Yönelik Bir Araştırma," Yüksek Lisans Tezi, İşletme Bölümü, İstanbul Üniversitesi, İstanbul, Türkiye, 2006.

[17] M. Terzi, “İş Sağlığı ve Güvenliği Politikası ile İş Tatmini Arasındaki İlişkinin Belirlenmesi: Ankara Sincan Organize Sanayi Bölgesindeki İşletmelere Yönelik Araştırma," Yüksek Lisans Tezi, İşletme Bölümü, Dumlupınar Üniversitesi, Kütahya, Türkiye, 2013.

[18] V. Arslan, "İnşaat Sektöründe İş Kazalarının Medyadaki Yansımaları ve Analizi," Yüksek Lisans Tezi, İnşaat Mühendisliği Bölümü, Anadolu Üniversitesi, Eskişehir, Türkiye, 2014.

[19] T. S. Koç, "İş Sağlığ1 ve Güvenliği Uygulamalarının Örgütsel Güven ve İş Tatminine Etkisi: Alanya'da Konaklama İşletmeleri Üzerine Bir Araştırma," Yüksek Lisans Tezi, İşletme Bölümü, Akdeniz Üniversitesi, Antalya, Türkiye, 2015.

[20] A. Yegin, "İş Güvenliği Kültürünün İş Kazalarına Etkileri,” Yüksek Lisans Tezi, İş Sağlığı ve Güvenliği Bölümü, Gedik Üniversitesi, İstanbul, Türkiye, 2015.

[21] B. Çiçek, "Hastanelerde Kurum Ev İdaresi Personeli Perspektifinden İş Sağlığ1 ve Güvenliği Uygulamalarının ve Güvenlik Kültürüne İlişkin Algı Düzeylerinin Belirlenmesi,” Yüksek Lisans Tezi, İş Sağlığı ve Güvenliği Bölümü, Hacettepe Üniversitesi, Ankara, Türkiye, 2016.

[22] A. Razgratlı, "İnşaat Sektöründe İş Kazalarının Psikolojik Sonuçları,” Yüksek Lisans Tezi, İnşaat Mühendisliği Bölümü, Beykent Üniversitesi, İstanbul, Türkiye, 2016.

[23] İ. Pehlivan, "İnşaat Sektöründe Çalışanların İş Sağlı̆̆ı ve Güvenliği Bilincinin İstatistiksel Olarak İncelenmesi,” Yüksek Lisans Tezi, İş Sağlı̆̆ı ve Güvenliği Bölümü, Gedik Üniversitesi, İstanbul, Türkiye, 2016.

[24] S. Sharma, Applied Multivariate Techniques, New York, USA: John Wiley \& Sons, 1996. 
[25] Ş. Kalaycı, SPSS Uygulamalı Çok Değişkenli İstatistik Teknikleri, Ankara, Türkiye: Asil Yayın Dağıtım, 2009.

[26] S. Yıldız ve M. Yılmaz, "Türk İnşaat Sektöründe Çalışanların Güvenlik Kültürü Düzeyinin ve Güvenlik Performansı ile İlişkisinin İncelenmesi,” Politeknik Dergisi, c. 20, s. 1, ss. 137-149, 2017.

[27] S. Dursun, "Güvenlik Kültürünün Güvenlik Performansı Üzerine Etkisine Yönelik Bir Uygulama,” Yüksek Lisans Tezi, İşletme Bölümü, Uludağ Üniversitesi, Bursa, 2011.

[28] K. Öztürk, "Orman Ürünleri Sanayi Sektöründe İş Sağlığ1 ve Güvenliğine Yönelik Çalışan Algısının İncelenmesi,” Yüksek Lisans Tezi, Orman Endüstri Mühendisliği Bölümü, Karadeniz Teknik Üniversitesi, Trabzon, 2016.

[29] J. I. Havold, "Safety Culture and Safety Management Aboard Tankers," Reliability Engineering And System Safety, s. 95, ss. 511-519, 2010. 